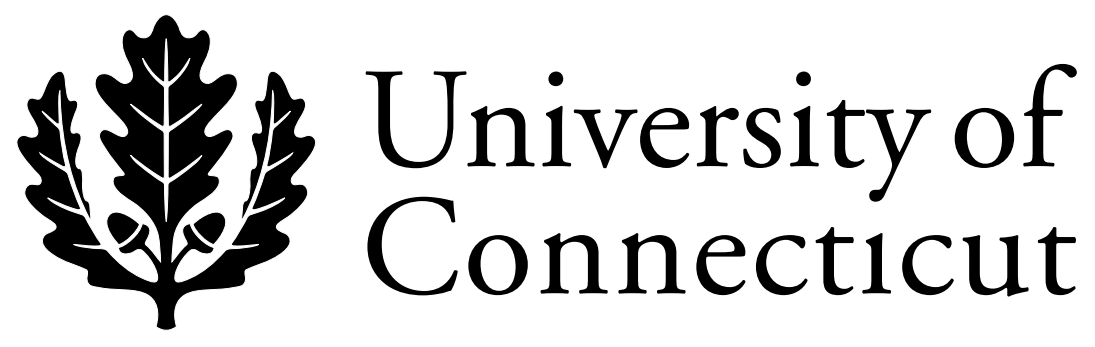

Department of Economics Working Paper Series

\title{
Modularity in Technology, Organization, and Society
}

Richard N. Langlois

University of Connecticut

Working Paper 1999-05

August 1999

341 Mansfield Road, Unit 1063

Storrs, CT 06269-1063

Phone: (860) 486-3022

Fax: (860) 486-4463

http://www.econ.uconn.edu/ 


\section{Introduction.}

Modularity is a very general set of principles for managing complexity. By breaking up a complex system into discrete pieces — which can then communicate with one another only through standardized interfaces within a standardized architecture - one can eliminate what would otherwise be an unmanageable spaghetti tangle of systemic interconnections.

Such ideas are not new in the literature of technological design (Simon 1962, Alexander 1964), even if, as some claim (Baldwin and Clark 1997), modularity is becoming more important today because of the increased complexity of modern technology. What is new is the application of the idea of modularity not only to technological design but also to organizational design. Sanchez and Mahoney (1996) go so far as to assert that modularity in the design of products leads to — or at least ought to lead to - modularity in the design of the organizations that produce such products.

From another angle, however, the principles of modularity have an even longer pedigree in the social sciences. We can think of Adam Smith's "obvious and simple system of natural liberty" as among the earliest proposals for how a complex modern society might be made more productive through a modular design of social and economic institutions. In separating mine from thine, rights of private property modularize social interaction, which is then mediated through the interface of voluntary exchange, all under the governance of the systems architecture of common law. Despite its heavy emphasis on incentive issues, the economics of property rights that emerged from the work of Coase $(1937,1960)$ — in both its original form (Furubotn and Pejovich 1972) and its 
more formal recent incarnation (Hart 1989) — provides a good deal of material useful for understanding the nature and role of modularity in social institutions.

A Venn diagram would reveal only the thinnest of overlaps between the management literature on modularity and the economics of property rights. The management literature asks how and why firms should design modular products and how they should organize themselves internally to cope with those modular products. The literature on (what is implicitly) modularity in social institutions asks how the interactions among organizational units should be structured to increase wealth and promote economic growth. The overlapping question, of course, is Coase's question: what determines the boundaries of organizations? Why are some (modular) social units governed by the architecture of the organization and some governed by the larger architecture of the market?

This paper is an attempt to raid both the literature on modular design and the literature on property rights to create the outlines of a modularity theory of the firm. This theory will look at firms, and other organizations, in terms of the partitioning of rights understood as protected spheres of authority - among cooperating parties. And it will assert that organizations reflect nonmodular structures, that is, structures in which decision rights, rights of alienation, and residual claims to income do not all reside in the same hands. The reasons behind alternative partitions are numerous and complex, however, calling for subtlety in the application of the idea of modularity to the firm. 


\section{Modularity and complexity.}

The world is full of complex systems. Nature provides an abundance of complex organisms and ecosystems, and humans have constructed complex mechanical, intellectual, organizational, and social systems. But what exactly does it mean for a system to be complex? F. A. Hayek holds that complexity is a function of the "minimum number of elements of which an instance of the pattern must consist in order to exhibit all the characteristic attributes of the class of patterns in question" (Hayek 1967, p. 25). Herbert Simon makes the same point in a less opaque and perhaps more helpful way: a complex system is "one made up of a large number of parts that interact in a nonsimple way. In such systems the whole is more than the sum of the parts, not in an ultimate, metaphysical sense but in the important pragmatic sense that, given the properties of the parts and the laws of their interaction, it is not a trivial matter to infer the properties of the

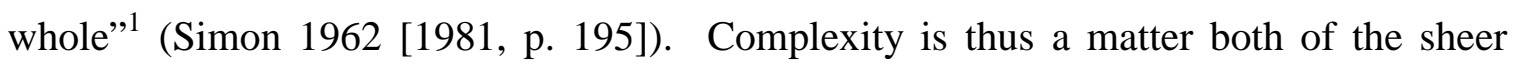
number of distinct parts the system comprises and of the nature of the interconnections or interdependencies among those parts.

One way to manage complexity, then, is to reduce the number of distinct elements in the system by grouping elements into — by hiding elements within — a smaller number of subsystems. Simon argues for the criterion of decomposability in modular design, which he offers both as a prescription for human designers and as a description of the systems we find ready-made in nature. To make the latter point he offers the parable

A point on which Hayek agrees: "Such 'wholes', defined in terms of certain general properties of their structure, will constitute distinctive objects of explanation for a theory, even though such a theory may be merely a particular way of fitting together statements about the relations between the individual elements" (Hayek 1967, p. 26; see also loc. cit., pp. 70-71). 
of the watchmakers. Tempus and Hora both make complicated watch-systems from myriad parts, and both are interrupted frequently in their work. Tempus does not design his watches as decomposable systems, so every time he is interrupted and forced to set aside his work, the entire unfinished assembly falls to pieces. By contrast, Hora first builds stable subassemblies that he can then put together in hierarchic fashion into larger stable subassemblies. Thus, when Hora is interrupted, only the last unfinished subassembly falls apart, preserving most of his earlier work. In an evolutionary selection environment, such stability would be rewarded with survival (Simon 1962 [1981, pp. 200-205]).

In the end, however, what makes Tempus's unfinished watches so unstable is not the sheer number of distinct parts involved. Rather, it is the interdependency among the parts in his design that cause the watches to fall apart. In a nondecomposable system, the successful operation of any given part is likely to depend on the characteristics of many other parts throughout the system. So when such a system is missing parts (because it is not finished, for example, or because some of the parts are damaged), the whole ceases to function and the system becomes evolutionary shark bait. In a decomposable system, by contrast, the proper working of a given part will depend with high probability on the characteristics of other parts within its subassembly — but will depend with relatively lower probability on the characteristics of parts outside of that subassembly. 2 As a result,

I won't elaborate the formalism, but this is clearly equivalent to saying that a decomposable system is one for which the matrix of interaction probabilities is decomposable. A nearly decomposable system - which is the best one could hope for in the real world - is one in which the probabilities of interaction within the subassembly (submatrix) are much higher than those of interaction outside of it. Simon (1962 [1981, pp. 210-212] makes this point with an example using heat-transfer coefficients rather than probabilities. See also Alexander (1964, especially pp. $111 \mathrm{ff}$.). 
a decomposable system may be able to limp along even if some subsystems are damaged or incomplete.

In organizational and social systems - and perhaps even in mechanical ones as well - it is possible to think of interdependency and interaction among the parts as a matter of information transmission or communication. Consider, with Eric von Hippel (1990), the problem of organizing product innovation. Here the issue is how to decompose the organization of a research and development project by partitioning tasks among development teams. As von Hippel points out, in order to solve this decomposition problem, one has to focus on the interdependencies among the various tasks the project comprises. interdependency will be high, meaning that each development team will need constantly to receive and use information about what all the other development teams are doing.

For example, the development of the OS/360 operating system for the original IBM 360 line of computers was evidently organized in a relatively nondecomposable way. The manager of the project, Frederick Brooks, insisted on a conscious attention to interdependencies and a high level of communication among all participants. This included the creation and maintenance of a formal project workbook that documented every aspect of the system so that, in principle at least, every worker could determine how changes elsewhere would affect his or her part of the project. Brooks decided "that each programmer should see all the material, i.e., should have a copy of the workbook in

3 von Hippel defines "the interdependence between any two innovation project tasks with respect to problem-solving as the probability that efforts to perform one of the tasks to specification will require related problem-solving in the other. The higher this probability in a given instance, the greater the problem-solving interdependence" (von Hippel 1990, p. 409). 
his own office" (Brooks 1975, p. 76). But within six months there was one small problem. "The workbook was about five feet thick! If we had stacked up the 100 copies serving programmers in our offices in Manhattan's Time-Life Building, they would have towered above the building itself. Furthermore, the daily change distributions averaged two inches, some 150 pages to be interfiled in the whole. Maintenance of the workbook began to take a significant time from each workday" (Brooks 1975, p. 77). The team soon switched to microfiche. And, clearly, with modern technology, the workbook could reside online and be updated rapidly. But the point remains that a nondecomposable system incurs high communications cost. Indeed, it is an insight for which Brooks is well known that, in the design of complex systems, the costs of communication among workers will eventually outweigh the benefits of the division of labor as more and more workers are added to a project (Brooks 1975, pp. 18-19).

At one point, Brooks briefly considers a "radical" alternative proposed by D. L. Parnas, whose "thesis is that the programmer is most effective if shielded from, rather than exposed to the details of construction of system parts other than his own" (Brooks 1975, p. 78). This radical alternative is in fact the strategy of seeking decomposability in the design of the development project and of the underlying software. Parnas (1972) is the inventor of the notion of information hiding, a key concept in the modern objectoriented approach to computer programming. Programmers had long understood the importance of modularity, that is, of breaking programs into manageable pieces. But a modular system is not automatically a decomposable one, since one can break the systems into modules whose internal workings remain highly interdependent with the internal workings of other modules. Parnas argued that, especially in large projects, 
programmers should abandon modularization based on simple flow charts and pay attention instead to minimizing interdependencies. If knowledge is hidden or encapsulated within a module, that knowledge cannot affect, and therefore need not be communicated to, other parts of a system. Under this scheme, every module "is characterized by its knowledge of a design decision which it hides from all others. Its interface or definition was chosen to reveal as little as possible about its inner workings" (Parnas 1972, p. 1056).

Recently, Baldwin and Clark (1997, p. 86) have drawn on similar ideas from computer science to formulate some general principles of modular systems design. The decomposition of a system into modules, they argue, should involve the partitioning of information into visible design rules and hidden design parameters. ${ }^{4}$ The visible design rules (or visible information) consist of three parts.

- An architecture specifies what modules will be part of the system and what their functions will be.

- Interfaces describe in detail how the modules will interact, including how they fit together and communicate.

- And standards test a module's conformity to design rules and measure the module's performance relative to other modules.

These visible pieces of information need to be widely shared and communicated. By contrast, the hidden design parameters are encapsulated within the modules, and they need not (indeed, should not) be communicated beyond the boundaries of the module.

As I've suggested, not all modular systems are decomposable. Baldwin and Clark - and most others - have in mind decomposable or nearly decomposable modular systems. From this point on, I will follow common usage and take modularity to imply if not decomposability at least the goal of decomposability. 
As Baldwin and Clark point out, the literature on modular systems tends to collapse these three kinds of information together, calling them all either "the architecture," "the interfaces," or "the standards." In order to have a single term for all three, I will refer to a set of architecture, interfaces, and standards as a modularization.

\section{Design processes.}

Clearly, modularity is a design structure with a great many advantages. By reducing the degree of interdependency among, and thus the costs of communicating across, the parts of a system, it gives full rein to the many benefits of the division of labor among components. As usual, however, there is no free lunch. It turns out that

modular systems are much more difficult to design than comparable interconnected systems. The designers of modular systems must know a great deal about the inner workings of the overall product or process in order to develop the visible design rules necessary to make the modules function as a whole. They have to specify those rules in advance. And while designs at the modular level are proceeding independently, it may seem that all is going well; problems with incomplete or imperfect modularization tend to appear only when the modules come together and work poorly as an integrated whole (Baldwin and Clark 1997, p. 86).

A well-decomposed modular system must pay a kind of fixed cost that an intertwined system need not pay, and this is true whether the system is brought to us by the evolutionary process or by a design team at Sony. Under some circumstances, the benefits of modularization may not be worth the cost. For example, a system whose environment never changes may not have to worry much about modularization: Tempus will do as well as Hora if neither is ever interrupted. Systems that develop slowly in a slowly changing environment may not acquire, or require, much modularity. 
As we saw, a nondecomposable complex system that is consciously designed (as by a development team) requires a great deal of communication among the designers. In another sense, the system itself also displays a great deal of "communication" among the parts, in that the functioning of one part is highly dependent on the functioning of parts elsewhere in the system. But when a system is not consciously designed and instead develops slowly over time, learning can take place in a way that involves far less explicit transmission of information. As Alexander suggests in the context of architecture and urban design, many of the most attractive and durable systems are those (often traditional) ones that develop through an "unselfconscious" process. Whether the object is a building or a computer operating system, a designer must set forth design rules explicitly and communicate them clearly. In the unselfconscious process, by contrast, "the rules are not made explicit, but are, as it were, revealed through the correction of mistakes" (Alexander 1964, p. 35). Inconsistencies and interdependencies are revealed not by ex ante communication but by trial-and-error.

Alexander seems to think that traditional designs developed by the unselfconscious process will also tend to be modular. This certainly can be so: the modular design of the earliest PCs, which influenced the design of the IBM PC, was not the result of any conscious design (Langlois 1992a). But it is by no means obvious that unselfconscious design must always, or even usually, result in modularity. ${ }^{6}$ Under stable

5 That complex systems can develop spontaneously through a process of trial and error should not come as a surprise to anyone who has studied Hayek or Karl Popper. On the latter's "evolutionary epistemology,” see Radnitzky and Bartley (1987).

6 In fact, one of Alexander's own examples of an unselfconscious traditional system is clearly nondecomposable. Slovakian peasants once made beautiful colored shawls using traditional techniques. In the early twentieth century, they replaced their traditional dyes with newly developed aniline ones - and "at once the glory of the shawls was spoiled; they were now no longer delicate 
conditions, indeed, a nonmodular system may present certain advantages to an unselfconscious process of trial-and-error. As Brooks points out in criticizing the Parnasian approach to software, "a good information system both exposes interface errors and stimulates their correction" (Brooks 1975, p. 78). To the extent that a nondecomposable system tends to reveal errors more quickly and more visibly, such a system may stimulate learning by doing in a way that modular systems do not. This is indeed the benefit of nondecomposability that Japanese manufacturing systems (including just-in-time inventory systems) are said to take advantage of. Since the failure of any one part can cause total system breakdown, nondecomposability raises the cost of missing or poorly functioning parts, which in turn raises the incentive to make sure that each part is of high quality. Nondecomposability also highlights bottlenecks and inconsistencies.

One would expect, however, that the benefits of nondecomposability would dominate those of modularity only for some kinds of relatively stable systems where frequent change isn't important. Although it did eventually have some modular aspects, Henry Ford's production system for the Model T was on the whole a finely tuned and nondecomposable system for cranking out large volumes of an undifferentiated product. In the 1920s, this system could not adapt well to changed market conditions and the (more modular) strategies of competitors, notably General Motors (Langlois and

and subtle, but crude" (Alexander 1964, p. 53). When small changes in one part of a system lead to such dramatic changes in functionality, nondecomposability is at work. Indeed, scholars from here to Santa Fe have become enthralled with the possibility that complex systems may often display this kind of "chaotic" behavior. Notice, however, that, since modularity tends to limit the transmission of spurious effects within a system, the widespread incidence of modular design diminishes the importance of the phenomenon of chaos. 
Robertson 1989). History offers many other examples of nondecomposable systems that developed by trial-and-error in stable environments.

\section{Encapsulation boundaries.}

In a world of change, modularity is generally worth the costs. The real issue is normally not whether to be modular but how to be modular. Which modularization, which structure of encapsulation boundaries, will yield the best system decomposition? The goal is clearly to find the modularization that minimizes interdependencies and most cleanly decomposes the system. But how to do this? How do we find the "natural" encapsulation boundaries? We would think it odd indeed to assign two interior designers each half of a room (von Hippel 1990, p. 410). It makes a good deal more sense either to give each designer a whole room or to give up encapsulation entirely and let the two designers communicate extensively.

The problem of defining boundaries of encapsulation becomes even more challenging in a dynamic setting. For example, the tasks in an innovative development project cannot be partitioned in advance, since knowledge is continually changing. ${ }^{\text {. }}$ In such a case, the modularization of the system (the development project) has to change continually; moreover, the modularization at any point has to take into account the inevitability of remodularization as learning takes place. In routine projects (like setting designers to work on a room), it may be possible to predict which tasks will become the sources of new information; but in genuinely novel projects, prediction becomes all but impossible. Indeed, unpredictable novelty may make any hard encapsulation undesirable,

\footnotetext{
$7 \quad$ This paragraph follows von Hippel (1990).
} 
calling instead for "loosely coupled" development teams of the sort evidently favored by Japanese companies $^{8}$ (Imai, Nonaka, and Pakeuchi 1985).

Of course, innovation need not always require or imply remodularization. In some cases, indeed, a fixed and predictable modularization can spur innovation. The personal computer is a case in point (Langlois and Robertson 1992, pp. 301-302). With the advent of the IBM PC in the early 1980s, the microcomputer became a modular system with a relatively fixed (or at least slowly changing) architecture, interfaces, and standards. Despite - or, rather, because of — the slowly changing character of the PC's basic structure, the industry experienced a phenomenal increase in value and reduction in cost arising almost entirely from improvements in modules (microprocessor, software, modems, peripherals, etc.) rather than from improvements in the way the modules connect together.

Innovation that takes place through change in the modules we can call modular innovation (Langlois and Robertson 1992, pp. 301-302; Sanchez and Mahoney 1996, pp. 68-69). This is in contrast to what Henderson and Clark (1990) call architectural innovation, in which the parts remain the same but the architecture connecting them changes. Notice, however, that architectural innovation need not always imply a change in the system's visible design rules: Legos and Tinkertoys are classic modular systems designed for architectural innovation. Here the architecture - the way the unchanging parts are recombined - can change without a fundamental change in the overall

8 In this context we can give a fairly precise meaning to this vague term: loosely coupled means modular but not fully decomposable. 
modularization. ${ }^{0}$ And, in fact, personal computers also benefit from the mix-and-match capabilities of a modular system that allow one to configure the system to taste as much as they do from improvement in the constituent modules (Langlois and Robertson 1992).

Sometimes, however, improving the functioning of a system calls for remodularization rather than recombination. Since a remodularization will render the existing stock of modules incompatible or irrelevant, systemic innovation comes at a cost. This indeed is one of the central insights of the much discussed literature on path dependency and technical standards. ${ }^{10}$ Can systems get stuck in an inferior modularization because of the costs of remodularization? The answer will no doubt depend on the context.

A related issue arises in a dynamic setting. As we have seen, well-decomposed modularity requires visible design rules that are fixed and unambiguous. If the design rules are in flux, the possibilities for modular innovation and mix-and-match recombination will be limited. On the other hand, freezing the design rules too early may result in an inferior modularization. Whether Scylla is preferable to Charybdis will again likely depend on the particular circumstances. In some cases, the benefits of modular innovation and recombination are so great as to outweigh mistakes in modularization. Many have argued that the IBM PC was not the best available platform of its day, but its

9 Clearly, the point of Legos and Tinkertoys is that the interfaces remain standard and unchanging. Whether "architecture" in the Baldwin and Clark sense (as opposed to the Henderson and Clark sense) also remains unchanged as the toys are assembled depends upon how finely one wants to parse the concept.

10 Buttressed by influential neoclassical models of network externalities (Katz and Shapiro 1985; Farrell and Saloner 1985), this intellectual edifice has as its keystone Paul David's (1985) famous history of the QWERTY keyboard. For critical perspectives, however, see Liebowitz and Margolis (1990, 1994); and for a general survey see David and Greenstein (1990). 
standardized modularity generated cost reductions and technical improvements at a rate that quickly left allegedly superior competitors in the dust (Langlois 1992a).

Garud and Jain (1996) have suggested the ideal of what they call a just-embedded system, that is, a system in which the visible design rules are enabling — firm enough to encourage modular innovation and recombination - but loose enough not to be constraining to the evolution of the system. This may be easier said than done. But in the case of personal computers, the three main interface standards - those of the microprocessor, the system bus, and the operating system - have in fact evolved gradually in a way that supported modular innovation.

\section{Social institutions and modularity.}

I have so far tried to consider the design of systems in the abstract, without clear reference to the kind of system or to the specific process of design. I now want to make the discussion more concrete by considering a particular kind of system: a society. My contention is that the theory of modular systems provides a useful way to look at the theory of social organization and to recast the classic debates in that literature.

The set of design rules that guide social interaction are what we can generally call social institutions (Langlois 1986). These rules determine (among other things) the extent to which, and the way in which, a society is a modular system. The desirability of modular design is a theme with a long history in the theory of social institutions. Adam Smith long ago proposed a decentralization scheme based on what he called "the obvious and simple system of natural liberty," by which he meant a system of private property regulated by common law and subject to minimal central administrative intervention. On 
the economic level, this approach would lead, he believed, to economic growth spurred by innovation, learning, and an ever-increasing division of labor (Smith 1976).

More recently, Hayek argued for similar principles in terms that draw even more explicitly on the theory of complex systems. Indeed, the benefits of information hiding lie at the base of Hayek's opposition to central planning, which he viewed as a cumbersome nondecomposable system ill-adapted to change. Because of the dispersed and often tacit character of the knowledge individuals must use, he argued, it is not only costly but ineffective to try to construct society as an intertwined system. "If we can agree that the economic problem of society is mainly one of rapid adaptation to changes in the particular circumstances of time and place," he wrote, "it would seem to follow that the ultimate decisions must be left to the people who are familiar with these circumstances, who know directly of the relevant changes and of the resources immediately available to meet them. We cannot expect that this problem will be solved by first communicating all this knowledge to a central board which, after integrating all knowledge, issues its orders. We must solve it by some form of decentralization" (Hayek 1945, p 524).

What makes decentralization economically effective is the possibility of a standard interface that allows the modules to coordinate with one another without communicating large volumes of information. This interface is the price system. "The most significant fact about this system is the economy of knowledge with which it operates, or how little the individual participants need to know in order to be able to take the right action. In abbreviated form, by a kind of symbol, only the most essential information is passed on and passed on only to those concerned" (Hayek 1945, pp. 526- 
527). But information hiding is not confined to the economic sphere. It is important in "nearly all truly social phenomena," including language and "most of our cultural inheritance." In all these areas, we "make constant use of formulas, symbols, and rules whose meaning we do not understand and through the use of which we avail ourselves of the assistance of knowledge which individually we do not possess" (Hayek 1945, p. 528) Abstract symbols and rules can provide a visible information structure that allows individuals to operate effectively on the basis of their more concrete (and hidden) information.

Despite the obvious significance to a theory of exchange of the rules of private property, it was not until the 1960s, with the publication of Ronald Coase's (1960) nowfamous article, that the economics profession discovered — or, at any rate, rediscovered — the need to think explicitly in institutional terms. The context of the article was the theory of external effects (or externalities) as developed in a dominant tradition emanating from the Cambridge economist A. C. Pigou. This theory concerned itself with the economic effects of conflicts in the use of property. To the extent that a property owner can affect others without paying the costs of those effects, the property owner's actions create "social costs" greater than their private costs. To the Pigovian economist, the divergence between social cost and private cost calls for direct government action (like a tax) to correct the inefficient behavior of the property owner. Coase pointed out that the problem of externalities actually traces to the rules of property themselves - to the way in which the domain of private action is modularized. In a world of perfectly decomposed property spheres, all interdependencies would flow through the interface of the price system: so long as property rights are complete and well defined, all conflicts in 
the use of property will be resolved through bargaining and exchange. But when the spheres of property are not well modularized - when property rights are absent, ambiguous, or ill defined — the initial assignment of property rights matters to efficiency. The symptoms of imperfect modularization came to be called transaction costs.

Coase's article also made a larger point. The right way to analyze the economics of conflicting uses of property is to think about the rules of property rather than about directly intervening in the decisions of the property owners. (Such intervention often corrects dependencies only at the expense of adding other dependencies — like a "patch" in a nonmodular software program.) Taxes and the like may sometimes be called for; but there are many other, often better, alternatives, including the extension, redefinition, or reassignment of property rights. This larger point, indeed, was the jumping off place for a new literature on the economics of property rights, one that concerned itself precisely with the nature and effects of the rules of property.

One of the earliest, and still one of the best, general treatments of property rights in this literature is that of Armen Alchian, who defines a system of property rights as "a method of assigning to particular individuals the 'authority' to select, for specific goods, any use from a nonprohibited class of uses" (Alchian 1965 [1977, p. 130]). The notion of authority is useful, as it tracks well the principle that, in a well-decomposed design, hidden system parameters ought to be under the control of the module only and not of

11 Barzel (1989, p. 2) defines transaction costs as "the costs associated with the transfer, capture, and protection of rights." This is by no means the only definition, but it is a particularly useful one in the present context. 
any other part of the larger system. Echoing a well-known maxim of liberal social thought, Alchian suggests drawing the boundaries so that each property owner has "the right to use goods (or transfer that right) in any way the owner wishes so long as the physical attributes or uses of all other people's private property is unaffected." 3

The economic benefits of carving out a protected sphere of authority fall into two broad categories, the "concentration of rewards and costs more directly on each person responsible for them," and "comparative advantage effects of specialized applications of ... knowledge in control, 14 (Alchian 1965 [1977, p. 140, emphasis original]). We might call these the incentive benefits and the division-of-knowledge benefits of property rights. Both are important, even if the first has attracted a disproportionate share of the attention of economists. I return to these issues below in the context of economic organization and the theory of the firm.

Coase's article focused on the exchange of property rights: under which circumstances will a right end up in the hands of the party who values it the most? But

12 For an early survey property rights approach, see Furubotn and Pejovich (1972). Other names for this literature include the law-and-economics tradition and the new institutional economics.

13 Notice that Alchian would limit the protection of property rights to infringements on the "physical attributes or uses" of one's rights. This is in fact quite standard in liberal theories of property rights. It rules out as non-infringing harms that are transmitted through the price system, what economists call pecuniary externalities. I may not burn down your restaurant (an interference with physical attributes), but I may open a restaurant next door and seduce away your clientele. Since such pecuniary effects are moderated through the interface of the price system, they create no unaccounted for cross-module interdependencies. In addition, Alchian (and others) would rule out intangible harms of a non-physical sort, what I once referred to as "transcendental" externalities (Langlois 1982). I may not pour effluent on your property; but I may in seclusion read material you find offensive, even though your knowledge that I do so harms you (lowers your utility) just as surely as does the effluent. As Amartya Sen (1970) showed in a classic article, to define harms in terms of the effects of one's actions on the utility functions of others is to vitiate completely the liberal idea of a protected sphere of action.

14 Alchian also mentions the comparative advantage effects of risk bearing, but I neglect this aspect of property rights here. 
the early literature springing from Coase's work also concerned itself with the creation and partitioning of rights. Economists have been well aware that the modular design of property rights comes at a cost, and that societies (and the economic agents within them) will want to pay that cost only if it is worth the benefit. Restaurant owners do not assert their full property rights over the salt they offer customers, but instead place the salt "in the public domain." Even though this destroys the patron's incentive to husband salt, any inefficiencies are dwarfed by the transaction costs of monitoring and charging for the use of the salt (Barzel 1989, p. 66). Harold Demsetz (1967) took this idea as the basis for a theory of the emergence of property rights. New rights will emerge (or old rights will be altered), he argued, whenever exogenous conditions conspire to make the costs of modularization worthwhile. In Demsetz's example, the Montagnes of Québec had no need for a property rights system until trade with Europeans in the seventeenth century increased the demand for beaver pelts and created a tragedy of the commons. In the postEuropean era, the benefits of property rights outweighed the costs (monitoring mostly), so the Montagnes adopted property rights. 15 They did this in order to internalize externalities, that is, to eliminate the effect of other people's actions on each hunter's management of beaver.

This same process also lies behind the bundling and unbundling of rights. Indeed, the creation of "new" rights and the rebundling of existing rights are really manifestations of the same underlying process of modularization, remodularization, and sometimes even

15 Douglass North (1990) and others would caution against a Panglossian interpretation of this theory, pointing out that entrenched interests and other sources of transaction costs can often prevent the adoption of new rights even when there would be considerable economic gains to doing so. Indeed, in historical and global perspective, the absence of potentially beneficial institutional change is the norm not the exception. 
demodularization. In all these cases, the driving objective is to internalize externalities, subject to the costs of setting up and maintaining the rights as well as to other considerations, notably the presence of economies of scale. Suppose, for example, that there are rampant externalities among a group of adjacent land owners. The owners could take account of these interactions by communicating among one another and negotiating contracts. This is clearly a nonmodular strategy: any new owner would face a web of restrictive covenants, and innovation that affected the nature of the externalities would require costly renegotiation. Alternatively, one of the owners could buy out the others, thus placing all the interactions within a single module, where presumably they could be dealt with more cheaply - with less negotiation costs and, perhaps more importantly, with less adverse effect on the ability and incentive to innovate.

Carl Dahlman's (1980) analysis of the medieval open-field system illustrates these points well. The open-field system dominated agricultural production (and therefore economic life) throughout Europe during the High Middle Ages. It was a complex system optimized for subsistence agriculture and near-autarkic production by manorial villages isolated from one another by high transport and transaction costs. The essence of the system was a fine partitioning and tailoring of rights to track the costs and benefits of the many different productive tasks on the manor. For some activities, like harvesting and the periodic grazing of cattle on fallow land, rights were held in common. This doesn't mean that the land was unowned like the beaver in Québec before the Europeans; rather, it means that actions were determined "collectively" by an elaborate set of management rules and practices evolved over time, overlain with a voting-based governance structure. For other activities, however, property was held privately, and the 
incomes of the peasants depended on the produce of particular parcels of land over which they held a residual claim.

Although each manorial village was a "module" in the medieval scheme of things, the open-field system was clearly not a decomposable system from the point of view of individual tenancy. Each peasant was an owner, but his rights were circumscribed by a thick web of restrictions and collective obligations. Since the system was adapted to a slowly changing environment, however, modularity would not have conferred much benefit. Moreover, the complex structure of the system was well optimized to its environment. For tasks with large economies of scale and low monitoring costs (like harvesting and grazing), management was collective. But for tasks involving low economies of scale and high monitoring costs (like cultivation and crop maintenance), high-powered ownership incentives prevailed.

As the Middle Ages wore on, inter-village transaction costs diminished and trade revived. This created gains from trade in specialization, which farming units could take advantage of only if they could reengineer themselves away from diversified subsistence agriculture. As North (1981) suggests, change proved nearly impossible despite the gains to be had; and it took a Malthusian crisis, including the death by plague of a third of Europe's population, to bring about a restructuring. The resulting enclosure movement involved in the main a voluntary unbundling of the complex relationships of the openfield system in favor of tenancy in fee simple, which not only allowed specialization but also aided modular innovation in agricultural and business practices. 16

16 Morris Silver (1984) has stressed the role of enclosure in overcoming the costs of and restrictions on innovation in what had been a nonmodular agricultural system. 
The open-field system is an example of what Michael Heller (1998) calls an anticommons. In a commons, like a beaver habitat without property boundaries, everyone has the unrestricted authority to use the resources in question. This results in the familiar tragedy of overuse. The anticommons, by contrast, is a situation in which no one has an unrestricted authority to use the resources; many people have the power to veto a proposed use. This results in an underutilization of the resource. Heller thinks the problem is that property rights have been partitioned into pieces that are too small. ${ }^{\square}$ The medieval peasant owned a right to the residual income of his strips, as well as (in the main) the right to sell strips to other peasants. But many pieces were sliced off the fee simple ideal, including the right to graze animals on the land in fallow years. Coase and Demsetz teach that, in the absence of transaction costs, rights cut too thin will quickly reassemble into optimal bundles. But if there are transaction costs, the rights may reassemble only with difficulty. Heller's examples include the granting of thinly chopped rights in the transition economies of Eastern Europe as well as some cases in intellectual property (Heller and Eisenberg 1998).

\section{Modularity and organization.}

In the property rights tradition, the theory of the firm is simply an application of the theory of the coalescence of property rights. Although it is seldom clearly spelled out, the starting point for analysis is typically a world of completely modular atomistic

17 There seems to me a distinction between saying that rights have been cut into too many pieces and saying that restrictions have been placed on a right. It is true that a restriction (a government land-use regulation, let us say) strips off a piece of the owner's right. But the piece stripped off is not necessarily in the form of a right that could in principle be tacked back on through exchange. In the cut-too-thin case, we would say that the system has been inefficiently modularized, and may or may not fix itself; in the restriction case, we would say that the system has been made less modular. 
production: each stage of production consists of an individual who owns the necessary physical capital (tools) and who coordinates his or her actions with other stages of production through arm's-length transaction. Why is not all production carried out this way? Coase's (1937) famous answer is that there is a (transaction) cost to using the price mechanism. If transaction costs are the costs of a bad modularization, what can go wrong with the atomistic modularization?

One early answer pursued the analogy with property law: the problem with the atomistic modularization is that, under some circumstances, there are externalities among the property owners that are best accounted for by the coalescence of property into one set of hands. In a famous example, Alchian and Demsetz (1972) suggest that the technology of production may lead to externalities: if production requires teamwork, and team work means that workers cannot cheaply observe one another's marginal product, then private incentives to shirk will generate a tragedy of the commons. A realignment of property rights solves the problem, as all but one of the teammates lose their residualclaim status and become wage earners; the remaining individual ceases to be a team member but specializes in monitoring, and is monitored in that task by his or her residual claim.

This formulation focuses on the incentive aspects of property, and it takes ownership to be equivalent to a claim on residual income (Foss and Foss 1998). Another view, originating as early as Coase (1937, pp. 391-392), sees ownership as involving not residual income streams but residual rights of control. Oliver Hart (1989) and his coauthors have lately championed this approach in a series of formal models. Because of uncertainty, no contract can foresee all possible contingencies. Thus there must be a 
residual right to make decisions in situations not covered by contract. That right is ownership, and ownership should be allocated to the party whose possession of it would maximize the joint surplus of production. ${ }^{.18}$

In Hart's story, the criterion for allocating ownership boils down to a matter of incentives. The pattern of the ownership of tangible (nonhuman) assets will affect the incentives of the parties to cooperate with one another. By altering the parameters of the "game" the parties play, a reallocation of residual rights of control over packages of nonhuman assets can improve cooperation and increase joint surplus. But there are, it seems to me, other reasons why reallocating residual control rights can improve efficiency. One is simply differential knowledge, something never considered seriously in the formal models. Even if no one is worried about the possibility of "hold-up" or the expropriation of rents, it still may be worthwhile to assign to only one of the parties the residual control rights over a package of assets if that party has comparative advantage in making the decisions.

Frank Knight (1921) suggested that comparative advantage might arise if one party possesses the superior faculty of judgment (Langlois and Cosgel 1993). But, ceteris paribus, genuine uncertainty — the prospect of or need for radical change - may by itself call for a consolidation of ownership. Stephen Littlechild provides one example.

[I]f I am quite sure what kinds of actions my neighbour contemplates, I might be indifferent between his owning the field at the bottom of my garden and my owning it but renting it out for him to graze his horse in. But once I take into account that he may discover some new use for the field that I haven't yet thought of, but would find objectionable, it will be

18 For a strikingly similar analysis more clearly influenced by the original property rights school, see Barzel (1987). 
in my interest to own the field so as to put the use of it under my own control. More generally, ownership of a resource reduces exposure to unexpected events. Property rights are a means of reducing uncertainty without needing to know precisely what the source or nature of the future concern will be. (Littlechild 1986, p. 35.)

There is also a flip side. Ownership may not only insulate one from certain kinds of unforeseen change, it may also enable one to generate radical change. I have tried to suggest on a number of occasions that concentrated ownership can overcome what I call the dynamic transaction costs of significant economic reorganization (Langlois 1992b). This is a motive for vertical integration little noticed in the literature.

These issues are important for the discussion to follow. But before turning to them, let me complicate matters a bit. Harold Demsetz has recently criticized Hart's approach for focusing too narrowly on residual of rights of control. "I should think that an asset would be 'owned' by the person who finds ownership most valuable," he writes, "but the value of the asset derives from the value of all rights in it and not just form residual control rights" (Demsetz, 1998, p. 448). Moreover, rights of control - even residual ones, he thinks - can in fact be parceled out to the same extent as can rights to use or rights to income streams. For Demsetz (1998, p. 451), the only difference between ownership of the residual rights of control and rental of those rights is that the former is a holding in perpetuity. In defense of Hart one might respond: can one ever really contract away genuine residual control rights, even temporarily? No matter how much discretion I am granted in a contract, there are some decisions I cannot make in response to unforeseen circumstances if I am a renter. A rental contract that allowed me to sell or destroy the asset over which I have control would be indistinguishable from a transfer of 
ownership. In the end, perhaps, residual control cannot be separated from the holding of control rights in perpetuity.

Nothing brings out the difficulties with the concept of ownership more clearly than does the modern public corporation. Who owns the corporation? Henry Hansmann (1996) makes a good case that it is the suppliers of capital, the holders of common stock, who possess a claim to residual income as well as some abstract or high-level rights of control. On the other hand, most of the day-to-day rights of control rest in the hands of hired managers. Demsetz has argued that managers are thus the de facto owners, since effective control is largely in their hands. "What shareholders really own are their shares and not the corporation" (Demsetz 1967, p. 359). From the point of view of theory, I tend to side with Hansmann and Hart. The shareholders "own" the corporation because they have the final say: managers cannot change the nature or strategy of the corporation in a radical way without the consent of stockholders, just as the renter cannot change without consent the use to which he puts Littlechild's field. From a pragmatic point of view, however, both are correct, in the sense that, in order to understand the corporation (and organization in general), we need to understand how and why decision rights are partitioned in collaborative enterprise.

Jensen and Meckling (1992) agree that the concept of ownership must involve not only the possession of decision rights but also the right to alienate those decision rights. Granting an individual both control and alienability is clearly a more complete modularization than granting control alone, since the owner with alienability needs to engage in less explicit coordination with others to use the asset effectively under all circumstances. In economics terms, it is alienability that solves both the problem of 
knowledge decentralization and the problem of incentives: the asset may be placed under the control of the person whose knowledge best equips him or her to use it, and alienability disciplines the owner's use of the asset by making its value (to which the owner has a residual claim) measurable on a market.

This is the basic modularization of the market economy. It accords well with the modularization G. B. Richardson (1972) suggested in offering the concept of economic capabilities. By capabilities Richardson means "knowledge, experience, and skills" (1972, p. 888), a notion related to what Jensen and Meckling (1992) call "specific" knowledge and to what Hayek (1945) called "knowledge of the particular circumstances of time and place." For the most part, Richardson argues, firms will tend to specialize in activities requiring similar capabilities, that is, "in activities for which their capabilities offer some comparative advantage" (Richardson 1972, p. 888).

So why don't we observe everywhere a perfectly atomistic modularization according to comparative advantage in capabilities - with no organizations of any significance, just workers wielding tools and trading in anonymous markets? We have already seen the outlines of several answers. The older property rights literature, we saw, would insist that the reason is externalities, notably the externalities of teamwork arising from the nature of the technology of production itself. The mainstream economics of organization is fixated on another possibility: because of highly specific assets, parties can threaten one another with pecuniary externalities ex post in a way that has real ex ante effects on efficiency (Klein, Crawford, and Alchian 1978; Williamson 1985). Richardson offers a somewhat different, and perhaps more fertile, alternative. Firms seek to specialize in activities for which their capabilities are similar; but production requires 
the coordination of complementary activities. Especially in a world of change, such coordination requires the transmission of information beyond what can be sent through the interface of the price system. As a consequence, qualitative coordination is necessary, and that need brings with it not only the organizational structure called the firm but also a variety of interfirm relationships and interconnections as well.

Whichever story one chooses, organization (in the broadest sense) arises as a nonmodular response to the fact of, or the need for, interactions among the modules. Organization is always a demodularization and repartitioning that severs the right of alienation from at least some of rights of decision. And, in all cases, the technology of production both causes and shapes the resulting non-modular interconnections.

\section{Modularity, organization, and technology.}

Sanchez and Mahoney (1996) contend that products design organizations. What they mean by this, roughly speaking, is that nonmodular products lead to or are best produced by nonmodular organizations, whereas modular products call for modular organizations. In a sense, however, this is a variant on what the mainstream economics of organization has long believed: production processes design organizations. If the production process requires team production or calls for highly specific assets, a nonmodular structure ("hierarchy") is in order; otherwise, a modular structure ("the market") is more appropriate.

In the case of Sanchez and Mahoney, at least, the notion that technology designs organizations is probably not as deterministic as it sounds. One can easily give the idea an evolutionary spin. Technology designs organizations in the same sense that the arctic 
designed polar bears: the bears emerged as structures well-enough adapted to, and therefore reflecting the nature of, the environment they faced. In my view, however, even this interpretation is too strong. In the case of technology and organization, sometimes polar bears can design the arctic.

On the one hand, it is true, for example, that IBM had to reinvent itself when it introduced the 360 line of computers in the 1960s (Langlois 1997). IBM had been a master of architectural innovation, able to recombine standard components to fit the customer's computing needs. Because of the bottleneck of writing software for many incompatible systems, however, the company chose a dramatically different strategy in introducing what was essentially a modular system. The 360 - referring to all the points of the compass - was a single basic system that, through modular recombination, could serve all purposes. Significantly, IBM adopted a distinctly nonmodular organizational structure to manage the 360 , although this may have to do with the fact that the 360 was an exclusively internal modular system: IBM worked hard to keep interfaces proprietary and to prevent others from supplying compatible modules.

On the other hand, however, vertically integrated computer companies in the 1970s and 80s kept trying to build personal computers on the nonmodular (or internally modular) model, not because personal computers ought to have been designed that way but because the imperatives of organization insisted. 9 This is even true of Apple, which

19 IBM itself originally tried to adapt organization to design by creating a small near-autonomous division to develop the original PC. But the company squandered its lead in the market because it could not subsequently fight the temptation to what Williamson (1985) calls "selective intervention," that is, the tendency to meddle with autonomous units. The result in this case was a series of idiosyncratic models that failed in the market. 
persists in building computers with less modularity than the competitors and (at least until recently) with very little external modularity at all (Langlois 1992a).

The automobile industry provides a number of interesting lessons about modularity and nonmodularity in organization and technology 20 Before the Model T, car manufacture was a highly modular enterprise; car makers were assemblers buying standard or easily modified parts from subcontractors. In this context, Henry Ford's invention of the moving assembly line and other high-volume production techniques was a remodularization of the manufacture of automobile parts. Ford and his engineers were inventing the process as they went along, and interfaces were necessarily in flux. Because of this, Ford needed authority and scope of action to bring about radical change quickly. By owning most of the stages of production, he was able to experiment with new techniques without paying the dynamic transaction costs of bringing outside players into the process. 1 Once the process of mass production crystallized, however, and change slowed, Ford realized that he could (re)decentralize production, albeit within the confines of the Ford organization.

As I mentioned earlier, Ford's finely tuned nonmodular structure of production did not adapt well to a world in which used cars began to compete with the undifferentiated Model T. General Motors responded to this challenge with a structure that was more modular, both in terms of the modular divisional structure of the M-form (Chandler 1977) but also in terms of a platform-based production strategy that allowed

20 The next few paragraphs draw on Langlois and Robertson (1989).

21 I have suggested elsewhere that the need for authority during periods of rapid remodularization often gives rise to the (highly nonmodular) form of organization Max Weber described as charismatic authority (Langlois 1998). Schumpeter called this entrepreneurship. 
product differentiation and annual model changes while still taking advantage of large production runs for common components (Raff 1991).

Nonetheless, from the 1930s on the American industry adopted on the whole a highly nonmodular structure of production. Consider the relationship between manufacturers and parts suppliers. In the American industry, suppliers were treated at arm's-length, with price a crucial point of negotiation. Successful bidders would be presented with detailed specifications, and would have no role in the design of the parts they produced let alone in the design of the overall automobile. Now, one could think this system modular in that it relied on the interface of the price system and required only a lean transmission of information between manufacturer and suppliers. In fact, however, this is clearly nonmodular from the point of view of design and production, since it centralized all design decisions and accorded supplies no protected sphere of authority and no hidden information. Suppliers could not be trusted to vary designs, since any changes would ramify dysfunctionally through the intertwined design and production of the automobile.

One of the central facts about the automobile industry in the last 15 years or so is that this contracting structure has changed. Influenced by Japanese methods of production and design, American firms have begun to adopt long-term relationships with suppliers that involve genuine collaboration (Womack, Jones, and Roos, 1990). Some commentators have played up the collaboration angle, suggesting that this successful new organizational response works because it eliminates the modularity of the market in favor of a nonmodular structure of intense communication of information. For example, 
Charles Sabel and his coauthors appear to see the matter exactly this way. Commenting on the new collaboration among manufacturers and suppliers in automobiles, they write:

This activity is not supported by clearly-drawn property rights: It is usually impossible to say who owns partly-finished designs, or the rights to determine use of a resident engineer's time, etc. Nothing suggests that dealings are governed by elaborate (relational) contracts - often considered a substitute for vertical integration as a governance mechanism - that distribute the burdens between the parties in case of a long list of contingencies and provide for arbitration in the case of disagreements. Rather, the response to problems is ... to try and solve them together (Helper, Macduffie, and Sabel 1999).

As I argued earlier, ambiguous boundaries are always necessary to some extent when learning is taking place. And neither manufacturer nor supplier may own complete (alienable) decision rights at any point in the process.

But it would be a mistake, I think, to read the essence of the new collaboration in automobiles as arising out of a demodularization in which encapsulation has been eliminated in favor of intense communication. Quite the opposite is the case. What distinguishes the new American collaboration, like Japanese collaboration before it, is increased modularity. Rather than handing suppliers detailed instructions, manufacturers now give suppliers interface specifications and then encourage them to design the parts as they see fit. So called first-tier suppliers may even be ceded authority for major components of the automobile (Womack, Jones, and Roos 1990). Although some collaboration and exchange of general knowledge takes place, the underlying design parameters of each part become hidden information from the perspective of the manufacturer. 


\section{A modularity theory of the firm?}

Here, then, is the modularity theory of the firm. Firms arise as islands of nonmodularity in a sea of modularity. ${ }^{2}$ They may do so in response to externalities arising from the likes of team production or asset specificity. More interestingly, firms may also arise in order to generate externalities, that is, to facilitate the communication of rich information for purposes of qualitative coordination, innovation, and remodularization. Hybrid forms like joint ventures and collaborative arrangements arise for similar reasons.

The notion that firms may come into being in order to create externalities requires some elaboration. Quite a number of writers have argued that the firm exists because it offers a special kind of information exchange that somehow generates more knowledge than the "sum" of the knowledge of the participating individuals (Aoki 1990). Thus, the web of externality and thick communication within the firm has benefits that outweigh those of greater decentralization. Many indeed are impressed with the almost mystical collectivist benefits of the firm as an institution, benefits allegedly arising from trust and commitment $^{23}$ (Hodgson 1998). "Firms exist," in this view, "because they provide a social community of voluntaristic action structured by organizing principles that are not reducible to individuals" (Kogut and Zander 1992, p. 384).

The approach from modularity is not inconsistent with this view. But some cautions are in order. For one thing, most if not all of the benefits claimed for social communities within firms have also been claimed for social communities across firms,

22 To put it more precisely, firms (and other organizations) are partitions of decision rights, alienability rights, and residual claims alternative to an atomistic modularization in which all three coincide.

23 An odd view of the firm indeed to readers of the Dilbert comic strip. 
including both geographical industrial districts (Marshall 1961; Saxenian 1994) and "virtual" industrial districts of professionals (von Hippel 1989; Savage 1994). Qualitative coordination and learning are always matters of combining the knowledge and ideas — the capabilities — of a variety of individuals and groups, sometimes leading to an "emergent" result. The social network of a firm can certainly achieve this kind of cross-fertilization, but it is necessarily limited (qua firm) to the capabilities within its boundaries. Interfirm networks, and indeed markets, can also engage in knowledge combinatorics, a process that modularity helps along; and such interfirm networks are not limited in the capabilities they can address. Moreover, not all firms fit the picture of a social learning community; more than a few better fit the image of a Weberian bureaucracy in which roles are fixed and knowledge flows strictly channeled.

Where does this leave us? The idea that the essence of the firm is nonmodularity seems to me a robust one. But it is not clear that there is any simple theory of the nature and causes of that nonmodularity. This paper has tried to set out, in perhaps too desultory fashion, many of the necessary building blocks. Scholars can use these (and other) building blocks to understand the partitioning of decision rights, alienability rights, and residual claims in particular real-world organizational structures. ${ }^{24}$ It is only fitting, after all, that the modularity theory of the firm should itself be a modular system.

24 I would offer as role models Dahlman's (1980) analysis of the open-field system and Savage's (1994; Savage and Robertson 1999; Langlois and Savage 1999) analysis of the professions. 


\section{References.}

Alchian, Armen. 1965. "Some Economics of Property Rights," Il Politico 30(4): 816-29, reprinted in idem, Economic Forces at Work. Indianapolis: Liberty Press, 1977, pp. 127-149.

Alchian, Armen, and Harold Demsetz. 1972. "Production, Information Costs, and Economic Organization," American Economic Review 62(5): 772-795

Alexander, Christopher. 1964. Notes on the Synthesis of Form. Cambridge: Harvard University Press.

Aoki, Masahiko. 1990. "The Participatory Generation of Information Rents and the Theory of the Firm," in Masahiko Aoki, Bo Gustaffson, and Oliver E. Williamson, eds., The Firm as a Nexus of Treaties. Los Angeles: Sage Publications.

Baldwin, Carliss Y., and Kim B. Clark. 1997. "Managing in an Age of Modularity," Harvard Business Review 75(5): 84-93 (September-October).

Barzel, Yoram. 1987. "The Entrepreneur's Reward for Self-Policing," Economic Inquiry 25: 103-116.

Barzel, Yoram. 1989. Economic Analysis of Property Rights. New York: Cambridge University Press.

Brooks, Frederick P. 1975. The Mythical Man-Month:Essays on Software Engineering. Reading: Addison-Wesley.

Chandler, Alfred D. 1977. The Visible Hand: the Managerial Revolution in American Business. Cambridge: The Belknap Press.

Coase, Ronald H. 1937. "The Nature of the Firm," Economica, N.S. 4: 386-405 (November).

Coase, Ronald H. 1960. "The Problem of Social Cost," Journal of Law and Economics 3: 1-44 October).

Dahlman, Carl. 1980. The Open Field System and Beyond. New York: Cambridge University Press.

David, Paul A. 1985. "Clio and the Economics of QWERTY," American Economic Review 75(2): 332-337.

David, Paul A., and Shane Greenstein. 1990. "The Economics of Compatibility Standards: An Introduction to Recent Research," Economics of Innovation and New Technology 1(1-2): 3-41. 
Demsetz, Harold. 1967. "Toward a Theory of Property Rights," American Economic Review 57: 347-359.

Demsetz, Harold. 1998. Book review of Oliver Hart, Firms, Contracts, and Financial Structure, Journal of Political Economy 106(2): 446-452.

Farrell, Joseph, and Garth Saloner 1985. "Standardization, Compatibility, and Innovation," Rand Journal of Economics 16(1): 70-83.

Foss, Kirsten, and Nicolai Foss. 1999. "Understanding Ownership: Residual Rights to Control and Appropriable Control Rights," Working Paper 99-4, Danish Research Unit for Industrial Dynamics, Copenhagen Business School, March. http://www.business.auc.dk/druid/druid-attach/pdf_files/99-4.pdf.

Furubotn, Eirik G., and Svetozar Pejovich. 1972. "Property Rights and Economic Theory: A Survey of Recent Literature," Journal of Economic Literature 10(4): 11371162.

Garud, Raghu, and Sanjay Jain. 1996. "The Embeddedness of Technological Systems," Advances in Strategic Management 13: 389-408.

Hansmann, Henry. 1996. The Ownership of Enterprise. Cambridge: the Belknap Press.

Hart, Oliver D. 1989. "An Economist's Perspective on the Theory of the Firm," Columbia Law Review 89(7): 1757-1774.

Hayek, F. A. 1945. "The Use of Knowledge in Society," American Economic Review 35(4): 519-530.

Hayek, F. A. 1967. Studies in Philosophy, Politics, and Economics. Chicago: The University of Chicago Press.

Heller, Michael A. 1998. "The Tragedy of the Anticommons: Property in the Transition from Marx to Markets," Harvard Law Review 111: 621-688 (January).

Heller, Michael A., and Rebecca S. Eisenberg. 1998. "Can Patents Deter Innovation? The Anticommons in Biomedical Research,” Science 280: 698-701 (1 May).

Helper, Susan, John Paul Macduffie, and Charles Sabel. 1999. 'Pragmatic Collaborations: Advancing Knowledge While Controlling Opportunism," Paper for the Meeting on Make versus Buy: The New Boundaries of the Firm, Columbia Law School, November 14, 1997.

Henderson, Rebecca M, and Kim B. Clark. 1990. "Architectural Innovation: the Reconfiguration of Existing Product Technologies and the Failure of Established Firms," Administrative Science Quarterly 35: 9-30. 
Hodgson, Geoffrey M. 1998. "Competence and Contract in the Theory of the Firm," Journal of Economic Behavior and Organization 35(2): 179-201.

Imai, Ken-ichi, Ikujiro Nonaka, and Hirotaka Takeuchi. 1985. "Managing the New Product Development Process: How Japanese Companies Learn and Unlearn," in Kim B. Clark, Robert H. Hayes, and Christopher Lorenz, eds., The Uneasy Alliance. Boston: Harvard Business School Press.

Jensen, Michael C., and William H. Meckling. 1992. "Specific and General Knowledge, and Organizational Structure," in Lars Werin and Hans Wijkander, eds., Contract Economics. Oxford: Basil Blackwell, pages 251-74.

Katz, Michael, and Carl Shapiro. 1985. "Network Externalities, Competition, and Compatibility," American Economic Review 75(3): 424-440.

Klein, Benjamin, Robert G. Crawford, and Armen Alchian. 1978. "Vertical Integration, Appropriable Rents, and the Competitive Contracting Process," Journal of Law and Economics 21(2): 297-326.

Knight, Frank H. 1921. Risk, Uncertainty and Profit. Chicago: University of Chicago Press.

Kogut, Bruce, and Udo Zander. 1992. "Knowledge of the Firm, Combinative Capabilities, and the Replication of Technology," Organization Science 3: 383397.

Langlois, Richard N. 1982. "Cost-Benefit Analysis, Environmentalism, and Rights," The Cato Journal 2(1): 279-300 (Spring).

Langlois, Richard N., ed. 1986. Economics as a Process: Essays in the New Institutional Economics. New York: Cambridge University Press.

Langlois, Richard N. 1992a. "External Economies and Economic Progress: The Case of the Microcomputer Industry," Business History Review 66(1): 1-50 (Spring).

Langlois, Richard N. 1992b. "Transaction-cost Economics in Real Time." Industrial and Corporate Change 1(1): 99-127.

Langlois, Richard N. 1997. "Cognition and Capabilities: Opportunities Seized and Missed in the History of the Computer Industry," in Raghu Garud, Praveen Nayyar, and Zur Shapira, eds., Technological Learning, Oversights and Foresights. New York: Cambridge University Press.

Langlois, Richard N. 1998. "Personal Capitalism as Charismatic Authority: the Organizational Economics of a Weberian Concept," Industrial and Corporate Change 7: 195-214. 
Langlois, Richard N., and Metin M. Cosgel. 1993. "Frank Knight on Risk, Uncertainty, and the Firm: A New Interpretation," Economic Inquiry 31: 456-465 (July).

Langlois, Richard N., and Paul L. Robertson. 1989. "Explaining Vertical Integration: Lessons from the American Automobile Industry," Journal of Economic History 49(2): $361-375$.

Langlois, Richard N., and Paul L. Robertson. 1992. "Networks and Innovation in a Modular System: Lessons from the Microcomputer and Stereo Component Industries," Research Policy 21(4): 297-313.

Langlois, Richard N., and Deborah A. Savage. 1999. "Standards, Modularity, and Innovation: the Case of Medical Practice," in Raghu Garud and Peter Karnøe, eds., Path Dependence and Path Creation. Hillsdale: Lawrence Erlbaum.

Liebowitz, S. J., and Stephen E. Margolis. 1990. "The Fable of the Keys," Journal of Law and Economics 33(1): 1-25 (April).

Liebowitz, S. J., and Stephen E. Margolis. 1994. "Network Externalities: An Uncommon Tragedy," Journal of Economic Perspectives 8(2): 133-150.

Littlechild, Stephen C. 1986. "Three Types of Market Process," in R. N. Langlois, ed., Economics as a Process: Essays in the New Institutional Economics. New York: Cambridge University Press.

Marshall, Alfred. 1961. Principles of Economics, 9th (variorum) ed., vol. I, London: Macmillan.

North, Douglass C. 1981. Structure and Change in Economic History. New York: Norton.

North, Douglass C. 1990. Institutions, Institutional Change, and Economic Performance. New York: Cambridge University Press.

Parnas, David L. 1972. "On the Criteria for Decomposing Systems into Modules," Communications of the ACM 15(12): 1053-1058 (December).

Radnitzky, Gerard, and W. W. Bartley, III. 1987. Evolutionary Epistemology, Rationality, and the Sociology of Knowledge. La Salle: Open Court.

Raff, Daniel M. G.. 1991. "Making Cars and Making Money in the Interwar Automobile Industry: Economies of Scale and Scope and the Manufacturing behind the Marketing," Business History Review 65(4): 721-753.

Richardson, G. B. 1972. “The Organization of Industry,” Economic Journal 82: 883-96. 
Sanchez, Ron, and Joseph T. Mahoney. 1996. "Modularity, Flexibility, and Knowledge Management in Product and Organizational Design," Strategic Management Journal 17: 63-76 (Winter Special Issue).

Savage, Deborah A. 1994. "The Professions in Theory and History: the Case of Pharmacy," Business and Economic History 23(2): 130-160 (Winter).

Savage, Deborah A., and Paul L. Robertson. 1999. "The Maintenance of Professional Authority: The Case of Physicians and Hospitals in the United States," in Paul L. Robertson, ed., Authority and Control in Modern Industry. London: Routledge.

Saxenian, AnnaLee. 1994. Regional Advantage: Culture and Competition in Silicon Valley and Route 128. Cambridge: Harvard University Press.

Sen, Amartya. 1970. "On the Impossibility of a Paretian Liberal," Journal of Political Economy 78(1): 152-157 (January-February).

Silver, Morris. 1984. Enterprise and the Scope of the Firm. London: Martin Robertson.

Simon, Herbert A. 1962. "The Architecture of Complexity," Proceedings of the American Philosophical Society 106: 467-482, repinted in idem, The Sciences of the Artificial, 2nd ed. Cambridge: MIT Press, 1981.

Smith, Adam. 1976. An Enquiry into the Nature and Causes of the Wealth of Nations. Glasgow edition. Oxford: Clarendon Press.

von Hippel, Eric. 1989. "Cooperation Between Rivals: Informal Know-how Trading," in Bo Carlsson, ed., Industrial Dynamics: Technological, Organizational, and Structural Changes in Industries and Firms. Dordrecht: Kluwer Academic Publishers.

von Hippel, Eric. 1990. "Task Partitioning: An Innovation Process Variable," Research Policy 19: 407-418.

Williamson, Oliver E. 1985. The Economic Institutions of Capitalism. New York: The Free Press.

Womack, James P., Daniel T. Jones, and Daniel Roos. 1990. The Machine that Changed the World. New York: Rawson Associates. 